\title{
Teaching Translation With the Notion of Discourse Analysis Under Different Communication Patterns
}

\author{
Chi-ying Chien ${ }^{1}$ \\ ${ }^{1}$ Department of Foreign Languages, Fooyin University, Kaohsiung, Taiwan (R.O.C.) \\ Correspondence: Chi-ying Chien, Department of Foreign Languages, Fooyin University, 151 Jinxue Rd., Daliao \\ Dist., Kaohsiung City 83102 , Taiwan (R.O.C.).
}

Received: September 5, 2018

Accepted: May 14, 2019 Online Published: May 16, 2019

doi: $10.5539 /$ elt.v12n6p128

URL: https://doi.org/10.5539/elt.v12n6p128

\begin{abstract}
The study of teaching translation has always been influenced by the theory of foreign language teaching, regardless of the theoretical or practical approaches the researchers used. In the classroom, students are frequently bored with translating grammar because they are seldom taught how grammar works. In view of this teaching gap, this study offers new translating skills for students to enhance their understanding and readability of the translated texts. Dr. Randy Pausch's "The Last Lecture," available in both video and text, was used as the study material because of the special language features of speech and written texts. Using Dr. Pausch's spoken and written material, the study adopted Hall's (1976) intercultural communication patterns together with discourse analyses by Halliday and Hasan (1976), so that students can learn how to analyze coherence and cohesion in their translations with different communication patterns. The subjects for this study were 80 English-major students, and the tools are four texts from Dr. Pausch's speech and published books. Data from student learning journals and their pre-test and post-test results were collected for statistical examination. Rather than simply translating words and following grammatical rules, the study provides new ideas for teaching translating, enhancing the quality of student translations by melding the latter with their personal experiences of the words they read and hear.
\end{abstract}

Keywords: discourse analysis, communication pattern, teaching translation

\section{Introduction}

Dr. Pausch's "The Last Lecture: Really Achieving Your Childhood Dreams" has several advantages for teaching translation. Neither a general descriptive article nor an academic study, it is an inspiring speech given by the author, his last 'lecture' at Carnegie Mellon University (CMU), where he taught for many years before dying of pancreatic cancer at the age of 47. Because of his enthusiastic, humorous, and inspirational attitude toward life, Dr. Pausch moved the audience to laughter and tears. Following Dr. Pausch's speech, an editor of the Wall Street Journal, Jeffrey Zaslow, called upon him to finish a written text version. The resulting book was full not only of inspirational content but included many unique phrases, expressions and anecdotes. For example, "My dad always taught me that when there's an elephant in the room, introduce them" or "(Being like) Meeting Captain Kirk." (Note 1) a childhood dream of Dr. Pausch's.

"I just thought it was fascinating as a kid that he had this thing [takes out Star Trek Communicator] and he could talk to the ship with it. I just thought that was just spectacular, and of course now I own one and it's smaller. [Takes out cell phone] So that's kind of cool." (The script was retrieved from Speakingfrog.com).

These anecdotes not only compelled the students' attention, they led to many discussions about how translating Dr. Pausch's speech should occur.

Translation is a conversion between two or more languages. Because of different language features between, say, English and Chinese, cohesion and coherence devices between the languages and the texts are essential for students to learn and to recognize not only superficial but subterranean meanings within the discourse.

The reason it is indeed a necessary learning procedure is because some students do not understand the importance of cohesion and coherence and the role they play in the translation process. This commonly results in an illogical text. The purpose of this study is to focus on cohesion and coherence analysis, using Dr. Pausch's speech and cross-cultural communication patterns to improve the students' translating skills. 


\section{Literature Review}

Due to the apparent but concise features in Dr. Pausch's oral presentation, students depend on context to make sense of what the speaker says and means. Sometimes they need to guess the meaning from the speaker's tone and body language. Indeed, information in written text is often easier and clearer to understand than oral speech. These contexts, divided into different patterns according to cross-cultural communication factors, are subject to discourse analysis, which helps students enhance their comprehension before they analyze and translate. Hence, the following literature review includes two sessions: discourse analysis and a cross-cultural communication model.

\subsection{Discourse Analysis}

Discourse analysis has been used to study and explore different word choices, translation skills, and translation motivation in the same text for different translators. Linguistic analysis in discourse has been provided by van Dijk, (1972), Halliday and Hasan (1976), Widdowson (1978), Brown and Yule (1983), Stubbs (1983), Coulthard (1985), and Givon (1995). Even so, different researchers use different definitions of the study of discourse analysis, and some have different interpretations of different texts. People commonly understand a discourse as either the spoken or written form of communication; but some researchers think a text is simply a paragraph of written and spoken text, and a discourse is a communication with a clear context. In other words, a text can be called a discourse within a context (Richards et al., 2000).

Linguists Halliday and Hasan (1976) state that the size of the translation unit is the way to distinguish between a text and discourse, the text being a small translation-unit, and discourse a large translation-unit. They believe that, if in two sentences, one sentence has the anaphoric function (that is, we can understand context by the use of pronouns), then the two sentences form a text because there is a cohesive relationship between them. Thus, apparently, a text is inseparable from its cohesion. Halliday (1985) further says that if there is a cohesive relationship among them, they can be treated as an analytical unit.

The above is concerned with the definition of a discourse. If a discourse is analyzed from the aspect of its function, then Halliday \& Hasan and Beaugrande \& Dressler (1981) believe it is a communicative occurrence. For the purposes of communication, there are seven main ideas in discourse: cohesion, coherence, acceptability, intentionality, situationally, informatively and intertextuality. Most linguists believe that cohesion and coherence are the most analytical techniques among them (Raphael, 1995; Halliday, 1985; van Dijk, 2004 \& 2005; Gee, 2010).

(1) According to Halliday and Hasan, cohesion devices include lexical cohesion and grammatical cohesion. Lexical cohesion uses related words chosen to link elements in a text and can be divided into reiteration, synonym, antonym, and collocation. Reiteration refers to the topic, and the focus of the message in the communication can be replaced by related words; for instance, "John's son" can be replaced by "the child." When the messages are repeated in subsequent sentences or paragraphs, synonyms and antonyms are also appropriate alternatives. The related words or phrases that generally go together are called collocation, and sometimes it is to refer to the same meaning. For example, the phrase "once upon a time" which replaces "before" or "long ago."

On the other hand, grammatical cohesion includes reference, ellipsis, substitution, and conjunction. The "reference" indicates the use of pronouns and deictic words (this, that, here, there) when a speaker or writer would like to avoid repeating words or nouns. Ellipsis refers to an elided form, which means that a writer or speaker elides pronouns, deictic words, and conjunctions, but the phrase might still have a natural cohesive effect in the context. Instead of the elided form, symbols can replace pronouns, deictic words, and conjunctions, such as the symbol "Ø." For example, "Slice the onion finely, brown Ø in the butter and then place Ø in a small dish" (Brown \& Yule, 2000, p. 175). Obviously, the symbol Ø means "onion" and is understood from the context. As for the conjunction, it includes the usages in compound and complex sentences. In compound sentences, equivalent or concatenated conjunctions are used, such as for, and, nor, but, or, yet, so. In complex sentences, subordinate conjunctions are used to connect the main and subordinate clauses, such as if, after, although, as, because, before, even if, even though ... and so on. Moreover, Halliday (1985) divides conjunctions into four types: they are additive (and, or, furthermore), adversative (but, however), causal (so, consequently), and temporal (then, finally, at last). They are also integrated into marked cohesive ties mentioned by Brown and Yule (2006). The last cohesion device is substitution, which occurs when a word is not omitted but substituted for another more general word, such as "one."

This works in an equivalent way with pronouns such as "it" to replace the noun. The difference between reference and substitution lies in that reference is a relation on the semantic level (level of meaning) and 
substitution is a relation on the lexicogrammatical level (grammar and vocabulary level). In its broadest sense, "a sort of counter which is used in place of the repetition of a particular item" refers to a kind of substitute (Halliday \& Hasan, 1994, p. 89). Because of these marked devices to show a semantic relation in the context, a cohesive power is needed to clarify some messages for readers. Therefore, we understand that, with the application of cohesive power, the logic in the context can be built in both the text and its translation (Gutwinski, 1976).

(2) Cohesion derives from the relationship among sentences and the usage of cohesion devices, which influence comprehension of the context and the equivalence of the original and target languages in deep structure. In contrast, the standard of coherence is used to decide the inner source of messages between two sentences, and the theme and the information structure (Halliday, 1994). The latter is divided into new and old, main and minor messages.

The following two sentences illustrate no cohesion and coherence:

a. It was a great lesson. Someone had to stay inside.

b. Robert took English and Chinese classes. He likes to go to Japan.

In the first example, there is no conjunction between the two sentences (no cohesion), and the theme and the information cannot generate a logical relationship (no coherence), which makes the context difficult to understand. In the second example, though the cohesive device is used (with pronoun "He") in the first sentence, the themes and information show an illogical and meaningless relationship between the two sentences. This is why Brinker (2005) defines cohesion in context and focuses on syntactic-semantic relations among sentences, whereas coherence relies on logic-semantic relations.

To treat problems of cohesion effectively, Shih (2008) applied Halliday's theory of functional grammar to show her students how to analyze texts. After her lecture, the students started learning about what kind of theme-rheme-patterns should be used to keep a complete structure and maintain semantic coherence in their translations. Moreover, students realized that, because Chinese is always simple and concise, they know how to add proper conjunctions according to punctuations used in Chinese texts. Even so, learning coherence is easier in translation than learning it relationally. Wang (2008) also adopts cohesion and coherence in college writing classes. However, she thinks lexical devices and referential devices should be used only for lexical connections when the effect of cohesion is not apparent. Only with Theme-Rheme theory can we embed the implication and real meaning for a better connection. Kim (2007) also used Theme-Rheme theory to teach students how to do text analyses. She found in their diaries that students were satisfied to learn how to translate with clear subjects, fluent language structures and tight content connections.

To sum up, the choice of theme would affect the development of the following discourse, and the wrong theme choice would lead to a mistaken message delivery between the original and its translation. Learning about cohesion and coherence would help define what kind of translation errors students make (for instance, lexical errors, grammatical errors, logic errors, semantic errors, or mistaken messages), and shows that translation practices can complement the theory of discourse analysis.

\subsection{Cross-Cultural Communication Model}

To study the quantity of information within the context, Hall (1976) was the first to apply the idea of high context and low context in cross-cultural communication theory. Hall believes that a country's culture has a deep relevance to how people communicate because social context influences behavior. Therefore, when most information in the communication relies substantially on context, Hall called it "High-context." In contrast, "Low-context" exists if most information can be understood clearly without any support from the context (Hall, 1990 \& 2000).

In high-context cultures, communicators are used to simplify or omit some information. Such information is known between the speaker and listener and there is the ever-present fear of information overload from the context. Moreover, it is hard to guess meaning from a high-context culture and communication: often listeners need to find the main points or implications by themselves. This is why Gudykunst and Ting-Toomey and Chua (1988) identified the features of the two communication patterns, and we can see the different functions between both patterns.

The features of high-context communication are as follows: 1) the purpose of communication lies mostly with emotional and persuasive expressions; 2) the speech is usually long and easy; 3) the main point cannot be understood as information delivery but can be understood within the context; 3 ) the listener and speaker are both satisfied with the ways of expression; 4) decision-making is based principally on emotions; 5) it is acceptable to interpret freely by both sides. 
On the other hand, the features of low-context communication are these: 1) the speaker's main point lies in the information; there is little more in the context; 2) listeners can find a lot of information on first hearing; 3) decision-making is based on how much information is heard; 4) if the speaker makes mistakes, the focus of the speech will be vague; 5) the interpretation of messages should be accurate on both sides.

In a high-context culture, the sources of information usually depend on support from the context rather than from the language itself. It is easy to find speakers repeating a topic because the message is vague and open to misunderstanding. Countries prone to high-context communication include France, Spain, Greece, and most Asian countries. On the other hand, in a low-context culture, the topics people talk about are often direct, precise, understandable, and focus on the principal points first. These countries include Switzerland, Scandinavia, Germany, and America, among others (Gudykunst \& Mody, 2002).

From the above discussion, we can more easily define the differences between high-context communicational patterns (HCCP) and low-context communicational patterns (LCCP). With the former, listeners need to pay attention to context - the speaker's/writer's voice and body language - to comprehensively understand what is being said. They need supporting messages to identify the main ideas and any deeper messages. With LCCP, however, listeners or readers can comprehend what is being read or said without support from the context.

There is no doubt that both patterns are used with international student training, cross-cultural educational training, and medical staff training. For instance, Kaplan (1966) applied this cultural thinking model to cross-cultural communication training; Chen and Starosta (1998) used it to train Korean bosses and subordinates how to solve cross-cultural conflicts; and Choe (2001) used this communication model as a method of problem-solving in the workplace to facilitate differences among cultures. Similarly, Kim, Pan and Park (1998) studied Chinese, American, and Korean cultures for international marketing under high- and low-context cultures. From the results, they confirmed Hall's theory that Chinese and Koreans are indeed inclined to HCCP, while Americans are mostly LCCP.

Clearly, many Asian countries, such as China and Japan, are high-context countries and heavily influenced by cultural values. Their people believe that discourse can be understood behind the words, even when communication is indirectly unspecified. People still catch what others say or think through body language, eye contact, and tone of voice. According to the theory of Chinese linguistics, cultural values and beliefs form the features of language and Chinese is connected by meanings and implications. Even so, the integration of ideas between sentences is not restricted by syntactic (grammar) constraints. Si-Guo (Note 2), a Chinese translator and professor active between the 1940s and 1970s, gave a wonderful metaphor for Chinese and English: long sentences in English are like a chain connected by many loops; Chinese, however, looks like pieces of a cake to be set untidily, where readers can see the sequence of the pieces automatically and rearrange them into meaningful units by means of their own understanding. In other words, the Chinese usually connect information according to the inner logic of the context. Although its structure is loose and the form tends to be concise, Chinese readers would take advantage of the many amplifications, such as metaphors, deep meanings, and emotions, to make up for any missing parts.

In short, the theory in the literature review shows that HCCP cannot be coded or delivered directly, cannot offer a clear explanation, nor provide sufficient references for in-depth background information. LCCP, by contrast, can be coded and delivered directly without additional interpretation.

\section{Method}

To explore Dr. Pausch's spoken and written texts, this study adopted Hall's (1976) intercultural communication patterns and the discourse analyses of Halliday and Hasan (1976). The purpose of applying this teaching method in the translation class was for students to understand the impact of cohesion and coherence on their translations under different communication patterns.

The study's participants are college students in their third year, who have learned basic translation skills and had some theoretical background. The texts chosen are important for the quality of their translations. Although there are many online translations offering versions of the speech video, this study uses only the Chinese simplified translation authorized by Dr. Pausch and from written texts. There are four study questions to reveal the impact of cohesion and coherence between two texts and two communicational patterns. (The two texts include the caption version online and the written version in the published book; two communication patterns include HCCP and LCCP.)

\subsection{Study Questions}

1) What is the impact of cohesion on translation between two communicational patterns? 
2). What is the impact of coherence on translation between two communicational patterns?

3). What are the different translation skills used in Chinese Simplified Caption and Traditional Version?

4). What are the learning results of using cohesion and coherence in student translations?

\subsection{Participants}

The researcher conducted content analysis of 80 22-year-old senior-level students, who were trained in basic translation skills for two years. Eighty students were divided into two groups, an experiment group and a comparative group, to investigate whether two communication patterns and discourse analyses work effectively, by raising their interest in learning and improving their translation skills. The two groups have been randomly placed according to the translation test given at the beginning of the semester.

\subsection{Teaching Procedure}

According to the study's aims, cohesion and coherence translation skills will be introduced to students in the experiment group, and different communication patterns will be considered to achieve improved solutions. Students will be introduced to the theories of intercultural communication patterns, cohesion, and coherence. Learning assignments for understanding the above will be introduced and discussed systematically. In addition, Dr. Pausch's live speech was played for both student groups to see how it differs in both Chinese versions. Before we considered translating the speech, however, the preface of "The Last Lecture" was discussed with students to show them what the impact of cohesion and coherence are on translation under HCCP and LCCP, respectively. Finally, both groups were requested to translate the speech and the published book in a pre- and post-test, comparing and reflecting on what was learned from their learning journals. Of course, repeated viewings of the video would be needed to reveal deeper messages when translating into Chinese.

\subsection{Data Collection}

This study adopts four texts of "The Last Lecture: Really Achieving Your Childhood Dreams" for analysis and comparison. The first is the live video on YouTube recorded on September 18, 2007, at Carnegie Mellon University in Pittsburgh. This is the "Live Speech Version" in this study. That year, Dr. Pausch authorized the rights to translate his speech to Lichao Chen for making a simplified Chinese caption, which was called "Chinese Simplified Caption." The following year, Jeffrey Zaslow, a Wall Street Journal reporter, published a book about Pausch entitled "The Last Lecture" on April 28, 2008, which became a New York Times best-seller. The book was translated and published in traditional Chinese on June 25, 2008, which was called "Chinese Traditional Version."

In this study, student assignments and data from a pre- and post-test were collected and used for the analysis. The following are the standards for data analysis:

1) Analysis of cohesion: data will be examined if it is reasonable to use the linking phrases or relative pronouns among sentence structures.

2) Analysis of coherence: data will be examined if students use logical thinking to include theme-rheme, new and old information among meaningful units.

3) Standard of HCCP: a context that requires listeners or readers to decipher using the context, voice, tone, and body language, for additional messages to be delivered.

4) Standard of LCCP: a context that is easily understood by listeners or writers without any context or other supporting messages.

\subsection{Research Instruments and Data Analyses}

To answer questions concerning the effectiveness of combining discourse and communicational patterns into translation training, the instruments used in this study consist of two main parts:

1) Calculating with coding: this was used to make comparisons of lexical cohesion and grammatical cohesion between the experimental and comparative groups.

2) Analyses of learning effectiveness on cohesion and coherence:

a) Independent $t$-test was applied to test the significance of the pre- and post-test.

b) Independent $t$-test was adopted, again, to test the error rate of coherence.

c) Student assignments were analyzed and used as examples for further discussion.

In this study, quantitative evaluation was measured before and after instruction. The scoring for translations by 
students is as follows: the students' acknowledgement of coherence (theme-rheme, new and old information) was 50 percent. Their acknowledgment of cohesion (conjunction, pronouns, relative pronouns, and relative adverbs) was also 50 percent. The above results were analyzed by SPSS 20.0 with Independent-Samples $t$-test to see if there is significance in cohesion and coherence.

Qualitative evaluation relied on student learning journals to identify what they had learned in the pre- and post-test and to determine (1) if students can properly identify communication patterns between HCCP and LCCP; (2) if students improved their performance in cohesion and coherence; (3) if discourse analysis benefits student learning and the quality of their translations; and (4) if the post-test is more readable than the pretest.

\section{Results}

This session covers four questions: 1) The impact of cohesion on translation; 2) The impact of coherence on translation; 3) The different translation skills used in the Chinese Simplified Caption and Chinese Traditional Version; and 4) The learning result of cohesion and coherence in students' translations.

\subsection{The Impact of Cohesion on Translation Under Two Communicational Patterns}

(1) Lexical and grammatical cohesion are found less in HCCP, as are the use of conjunctions, but it tends to be more concise with sentences in HCCP. The following quote from the Dr. Pausch's speech, "I know what the quality control is for real encyclopedias. They let me in," was translated as "I realized the real quality for controlling encyclopedias. They allow me to write" in Chinese simplified caption. This encourages readers to think further between the original text and the caption because the latter part of the sentence seems to be unconnected with the former part in the Chinese Simplified Caption. The actual story is that Dr. Pausch felt that the editor did not take the writing of encyclopedias sufficiently seriously, so they let him write for the encyclopedia without investigation. From the above two HCCP discourses, it is easy to find the deeper meaning or the speaker's ironic usage, which relies significantly on the context or the speaker's voice because of less lexical and grammar cohesion in the speech and caption.

(2) Lexical and grammatical cohesion are found more often in LCCP, which is easily understood. An example in Dr. Pausch's speech is:

"And the other thing about football is we send our kids out to play football or soccer or swimming or whatever it is, and it's the first example of what I'm going to call a head fake, or indirect learning."

Four conjunctions "or" in the speech were translated in the caption. However, in the Chinese Traditional Version "Whether they like football, soccer, swimming, or other sports, generally, we are not eager to wish them to excel in that sport..." (Chen, 2008), which only applied punctuation of commas to replace the translation of many conjunctions "or." We still find many lexical and grammar cohesions used in LCCP, which makes the reader sense some redundancy if the conjunctions are all translated in the context.

(3) Apart from conjunctions in grammar cohesion, there are many "references" used in LCCP. The usage of pronouns and deictic words (this, that, here, there) in the original are often omitted in the translation, which still achieves the effect of cohesion in the texts. The reason for this is due to the different natures of English, with its strict grammar, and Chinese, with its distinctive feature of imaginatively connecting meanings among sentences without too many restrictions in Chinese grammar. For instance, "Have something to bring to the table, because that will make you more welcome" (Pausch \& Zaslow, 2008, p. 33), and its translation in traditional Chinese "Don't forget to benefit others because if so, people would love making friends with you." (Chen, 2008). The deictic word "that" in the original disappeared in the translation. The purpose of omitting "that" in the translation is that the skill of ellipsis helps concision and the grammar is often minor. Indeed, students tended to translate all the pronouns and deictic words such as "because that will make you more welcome," rendering the target language redundant.

\subsection{The Impact of Coherence on Translation Under Two Communicational Patterns}

According to Halliday (1994), the purpose of coherence is to analyze the inner logic of the theme and information structure. Brinker (2005) stated that finding logic and meaning in the context will achieve coherence in the discourse. For connecting meanings in the context and finding logic in sentences, no matter what the HCCP or LCCP is, translation in both texts cannot be too simple or too close to the lexical meaning. This is because a translation that is too simple or too lexical would confuse the reader. Translation coherence skill tests not only the students' comprehension of the original, but the expressiveness of the target language. For example, in Dr. Pausch's speech,

“(Shows slide) (Being like) Meeting Captain Kirk. At a certain point, you just realize there are some things you 
are not going to do, so maybe you just want to stand close to the people,"

The translation in Chinese Simplified Caption is "the slide shows [become and meet Captain Kirk]." Dr. Pausch used symbols and pictures to support his intention, and the translation in HCCP directs people to think more deeply about the information he conveyed. The other example for HCCP is the use of slang. For instance, the discourse in the speech:

"So, you know, in case there's anybody who wandered in and doesn't know the back story, my dad always taught me that when there's an elephant in the room, introduce them."

The translation in the Chinese Simplified Caption used a note to annotate what this slang means. In the Chinese Traditional Version, the slang was close to the meaning of the original "Once we know something but we find it hard to talk about, then just go ahead to [open the skylight to speak up] (means to get to the point)." We can understand that the purpose of the translation skill to use coherence in the discourse is to translate and express precisely what is said.

Metaphors are another challenge to students when translating. Rhetorician I. A. Richards (1937) describes a metaphor in two parts: the tenor and the vehicle. The tenor is the main subject illuminated by the actual figurative expression (the vehicle). Both can explore the true meaning and convey correct information only when the tenor and the vehicle have good mutual collocation. In his speech, Dr. Pausch said,

"The brick walls are there to give us a chance to show how badly we want something. Because the brick walls are there to stop the people who don't want it badly enough. They're there to stop the other people."

What does "the other people" mean? If it was translated as it was in the caption "those other men," it is confusing to listeners and readers. Clearly, this relies substantially on an analysis of coherence to find the new and old information in the discourse. The old information is the people who are not eager to own it, and the new information, "the other people", indicates those who are not confident enough to achieve their goals, so they will be prevented from overcoming the brick walls.

\subsection{The Different Translation Skills Used in Chinese Simplified Caption and Traditional Version?}

After discourse analysis of the caption and written test, the research found that both have apparent differences with lexical or grammar cohesions, and try to reduce the cohesive devices to reach an effect of conciseness. However, grammar cohesion in the Chinese Traditional Version is less than half in The Last Lecture (English) under LCCP, so are the total numbers, as shown in Table 1 - an example analyzed in Chapter 8 "You'll Find Me Under V":

Table 1. The usage of cohesion devices

\begin{tabular}{|c|c|c|c|c|c|c|c|c|}
\hline \multirow{2}{*}{$\begin{array}{l}\text { Discourse } \\
\text { Cohesion }\end{array}$} & \multicolumn{2}{|c|}{ Live Speech } & \multicolumn{2}{|c|}{$\begin{array}{l}\text { The Caption } \\
\text { (Chinese Simplified) }\end{array}$} & \multicolumn{2}{|c|}{$\begin{array}{l}\text { The Last Lecture } \\
\text { (English) }\end{array}$} & \multicolumn{2}{|c|}{$\begin{array}{l}\text { The Last Lecture } \\
\text { (Chinese Traditional) }\end{array}$} \\
\hline & $\mathrm{LC}$ & GC & $\mathrm{LC}$ & GC & $\mathrm{LC}$ & GC & $\mathrm{LC}$ & GC \\
\hline LCCP & 5 & 10 & 4 & 10 & 25 & 34 & 21 & 13 \\
\hline HCCP & 3 & 5 & 2 & 3 & 7 & 10 & 6 & 8 \\
\hline Total & 8 & 15 & 6 & 13 & 32 & 44 & 27 & 21 \\
\hline
\end{tabular}

$\mathrm{L}=$ lexical Cohesion; $\mathrm{G}=$ Grammar Cohesion.

If we further analyze, looking for greater detail, we find that reiterations were used more in lexical cohesion, followed by synonyms. Similarly, references were used more in grammar cohesion, followed by conjunctions (See Table 2). Because Chinese and English belong to two language types, they have different structures and expressions, and so do their cohesive ways. In Table 2, the number of reiterations is almost equal in both the original and Chinese Traditional Versions, but the number of synonyms in the Chinese Traditional Version is fewer than in the original (seven in the original and one in the target language). 
Table 2. Details about lexical and grammar cohesion

\begin{tabular}{lllll|llll}
\hline Cohesion & \multicolumn{4}{c|}{ Lexical Cohesion } & \multicolumn{4}{c}{ Grammar Cohesion } \\
& Reiteration & Synonymy & Antonym & Collocation & reference & conjunction & ellipsis & substitution \\
\hline Live Speech & 7 & 1 & 0 & 0 & 8 & 4 & 0 & 2 \\
caption & 4 & 2 & 0 & 0 & 4 & 5 & 1 & 2 \\
The Last Lecture & 23 & 7 & 1 & 1 & 28 & 6 & 3 & 4 \\
Chinese & 24 & 1 & 1 & 1 & 9 & 5 & 1 & 3 \\
Traditional & & & & & & & & \\
\hline
\end{tabular}

However, for grammar cohesion, the use of reference in both caption and Chinese Traditional Versions is much less than in the original. From the above, we see the impact of language features of Chinese and English on translation in the caption and Chinese Traditional Versions.

Halliday and Hasan (2001) divided cohesion into overt cohesion and covert cohesion. Overt cohesion indicates that there are apparent devices (marks) to be shown in the discourse for proper connections, and lexical cohesion and grammar cohesion keep their characteristics in the discourse. Although some phrases such as "in fact" and "for example" were not listed in the cohesion range proposed by Halliday, they are still cohesion devices. Thus, because English emphasizes rules and regulations to reach a grammar connection, English has overt cohesion. We find proof for this in the published written version of "The Last Lecture," where cohesion devices are used more often in the text than in live speech.

On the other hand, covert cohesion is a way to reach connected effects without any devices shown in the discourse. For example, there are some usages in ellipsis, as well as in substitutions of themes and information that focus on grammar cohesion (Yu, 2007; Hu, 2014). We used to recognize the characteristic of Chinese as a covert cohesion. Compared with overt cohesion, the use of covert cohesion is less frequent, and sometimes there is no cohesive device because some elements in the context (such as logic, order, and new/old information) would assist readers in deciphering the discourse. Chinese prefers covert rather than overt cohesion, making the target language more concise but without omitting any information in the context. We can find proof that lexical and grammar cohesion in the Chinese Simplified Caption and Chinese Traditional Version are significantly less than in the originals (live speech and the published versions of "The Last Lecture").

\subsection{The Learning Results of Cohesion and Coherence in Students' Translation}

(1) For measuring their learning results, statistical analysis was used to examine the significance between the pre- and post-test and the improvement in translation. At the beginning of the study, an independent $t$-test was applied to test translation scores in a pre-test between the two groups and it revealed no significance $(t=0.769$, $\mathrm{p}>.05$ ), which means that the gap in English abilities did not reach significance.

Due to the above result, an independent t-test was used to test for further significance on a post-test, shown in Table 3. It was found that, in the experimental group, not only the mean was higher than that in the comparative group, but the score of the post-test in both groups reaches significance $(t=3.13, p<.01)$, which means that learning cohesion in the experimental group is more effective than in the comparative group. In addition, to understand why the learning performance of cohesion in the experimental group is better than in comparative group, the researcher made a further comparison in Table 4. (Reit: Reiteration, Syno: Synonym, Anto: Antonym, Coll: Collocation, Refe: Reference, Elli: Ellipsis, Subs: Substitution, Conj: Conjunction).

Table 3. Result of $t$-test for post-test between two groups

\begin{tabular}{lllll}
\hline Group & number & $\begin{array}{l}t \text {-value } \\
\text { (two-tail) }\end{array}$ & df & Significance \\
\hline Experimental & $(\mathrm{n}=40)$ & $3.13^{* *}$ & 38 & .012 \\
Comparative & $(\mathrm{n}=40)$ & 1.31 & 38 & .196 \\
\hline
\end{tabular}

${ }^{* *} \mathrm{p}<.01$ n.s. $\mathrm{p}>.05$ 
Table 4. Comparison for both groups' cohesion usage in post-test

\begin{tabular}{lllllllll}
\hline Groups & Cohesion & & & & & & & \\
\hline & Reit & Syno & Anto & Coll & Refe & Elli & Subs & Conj \\
\hline Experimental & 28 & 3 & 2 & 6 & 12 & 17 & 4 & 13 \\
Comparative & 25 & 1 & 0 & 0 & 15 & 2 & 0 & 18 \\
\hline
\end{tabular}

The above table shows the learning results after we finished the lecture of cohesion in the experimental group: the experimental group has more diverse cohesion usage than the comparative group (there is no proof using antonym, collocation, substitution in comparative group). Indeed, the adoption of reference and conjunction in the experimental group is less than in the comparative group, and ellipsis and substitution are more frequent than in the comparative group, which means students in the experimental group tended to reach concision in their translation with less usage of reference and conjunction, but to be cohesive in their translation they used more ellipsis and substitution.

(2) The other aspect is coherence analysis, which enhances comprehension or readability from the inner source of messages between two sentences, and theme and the information structure are essential for such analysis to occur (Halliday, 1994). In addition, Brinker (2005) stated that coherence studies "logic-semantic relations" in context. In this study, the analysis of theme observed if students can identify the correct theme in English and translate it into Chinese; the analysis of the information structure is to observe if students can tell the difference between new and old information and translate into Chinese. To understand if coherence can improve students' learning and enhance their comprehension in the experimental group, this study applied an independent $t$-test to test the error-rate of coherence.

The error-rate of coherence has been presented by errors of theme and errors of information. Both errors in the sentences, which numbered forty-one, in the test paper were the result of the error-rate of coherence. The result from the pre- and post-test is shown in Table 5, which reveals that the theme error-rate did not reach significance between the pre- and post-test. However, the information error-rate was significant between the two tests, and the decision-making of conversion between new and old information in translation in the post-test was better than in the pre-test $(t=3.437, \mathrm{p}<.05)$.

Table 5. Independent $t$ test for error rate of coherence

\begin{tabular}{|c|c|c|c|c|c|}
\hline Coherence & Tests & & (Overall & & lance) \\
\hline & & Mean & SD & Sig & $t$-value \\
\hline \multirow{2}{*}{ Theme } & Pre- & .0448 & .0130 & \multirow{2}{*}{0.157} & \multirow{2}{*}{$1.476^{\text {n.s }}$} \\
\hline & Post- & .0360 & .0137 & & \\
\hline \multirow{2}{*}{ Information } & Pre- & .1768 & .0600 & \multirow{2}{*}{0.003} & \multirow{2}{*}{$3.437^{* *}$} \\
\hline & Post- & .0892 & .0438 & & \\
\hline
\end{tabular}

n.s. $p>.05{ }^{* *} \mathrm{p}<.05$.

(3) According to the results, overall performance was higher in the experimental group when the students applied cohesion and coherence in their translation. The following are some examples, taken from their learning journals as well as their opinions, which highlight the qualitative results.

a. We found students in the experimental group were good at adopting ellipsis in their translations and the conjunction "and" is often omitted; for example, in Dr. Pausch's speech,

"And there I am, and for those of you who are into foreshadowing, this is the Alice ride. And I just thought this was just the coolest environment I had ever been in, and instead of saying, gee, I want to experience this, I said, I want to make stuff like this."

In contrast, conjunctions are used less often in Chinese (either Chinese Simplified Caption or Chinese Traditional Version) because it would not simply reduce the smoothness of the reading but add redundancy in the translation. Furthermore, students found that they cannot have cohesion and connect meaning effectively if 
conjunctions were translated improperly or were placed incorrectly in the discourse.

b. In the discourse, cohesion in the translation would not work well if one failed to express the previous sentence accurately. For instance, Dr. Pausch talked about the idea of the brick walls and the "people" in the first part of the sentence should be identified, then we can understand what the author or speaker means by "the other people."

c. The students had some difficulty translating the captions as revealed by their self-reflections in their learning journals. The translation of a caption needs to consider where to cut information appropriately and find a chunk and unit for readability in the translation. Not only information chunks but also the author's speaking style can make an effective interpretation of the speaker. With some spoken discourse, especially, the restriction of words and images on screen may contribute to a lack of a comprehensive meaning. We suggest, therefore, to add more words (amplification) for sound discourse.

d. Being good at using collocations for clear interpretation. For example, Dr. Pausch: "Because I am good, but I'm not good enough to talk about that without tearing up," one student's translation in the experimental group was: "Although I am fine mentally and physically now, I haven't been brave and strong enough to talk about them without tearing up." The best part of the student's translation lay with identifying the levels of "good," rather than just translating them as "good conditions."

e. In written texts, students tended to translate using long and additional sentences to retain the same words and structure as the original, and often would risk missing the writer's main ideas. It is best to apply more ellipsis of conjunctions and pronouns or synonyms of short phrases to replace or keep close to the main ideas, and avoid the restrictions of the original words or structure. Only when cohesion and coherence are learned and are applied to the translation can students assimilate the main ideas into the target language with an accurate interpretation.

Although this study investigated and discussed the different emphases of cohesion and coherence, both are related. Once the information in the discourse was understood as mistaken, the problem of coherence affected the discourse semantics. This reflected the importance that English focuses on grammar, and because of this, the training of cohesion and conference is necessary for Chinese translation skills.

\section{Conclusions and Recommendations}

This study used different texts, one aura/visual, the other written, from Dr. Randy Pausch's "The Last Lecture" to give students instructions concerning discourse analyses and to show which translation skills they need under different communication patterns. Theories from Hall (1976) and Halliday and Hasan (1976) were used to analyze different translation skills in Chinese Simplified Caption and a Chinese Traditional Version. The following are the study's conclusions: (1) lexical cohesion and grammar cohesion are used less in HCCP, making it more concise and simple in the discourse. We recommend adding further translations to clarify the main ideas. Indeed, we found that cohesion devices are used variously and are easy to tell in LCCP. However, we endorse omitting pronouns and demonstrative pronouns in translation, to reach both effects of cohesion and concision. In addition, there are symbols, photos, slang, and metaphors to be used in HCCP, and we would advise students to express clearly by presenting the whole picture with proper coherence.

After the discourse analysis of both translation texts, significant differences between the Chinese Simplified Caption and the Chinese Traditional Version were evident in identical increases in lexical cohesion. Decreases in references and conjunctions in grammar cohesion would be better for achieving concision in Chinese. Although students have learned how to adopt cohesion and coherence in the discourse translation, they easily made mistakes finding the correct information, especially in HCCP. This is why Chang (1999) reminded us that "In practical translation work, the translator is both a receptor from the original language, and a producer for the target language. So, it is necessary for a translator to take discourse analyses in the original language and so does in the target language to compare both sides before having the task down completely." To conclude, this study shows how to improve student translation skills through discourse analyses under HCCP and LCCP. Furthermore, the training of cohesion and coherence will help students to self-reflect before translating and to analyze more effectively for improved translation quality.

\section{References}

Beaugrande, R., \& Dressler, W. (1981). Introduction to Text Linguistics. London: Longman. https://doi.org/10.4324/9781315835839

Brinker, K. (2005). Linguistische Textanalyse. Eine Einführung in Grundbegriffe und Methoden (6th ed.). Berlin: Erich Schmidt Verlag. 
Brown, G., \& Yule, G. (1983). Discourse Analysis. Cambridge: Cambridge University Press. https://doi.org/10.1017/CBO9780511805226

Chang, M. F. (1999). Observing Limitations of Dynamic Equivalence from Context Analysis. Shanghai Technology Translation, 4, 35.

Chen, G., \& Starosta, W. (1998). Foundations of Intercultural Communication. Boston: Allyn and Bacon.

Choe, Y. (2001). Intercultural conflict patterns and intercultural training implications for Koreans. Paper presented at the 16th Biennial World Communication Association Conference, Cantabria, Spain.

Coulthard, M. (1985). An Introduction to Discourse Analysis (2th ed.). London: Longman.

Gee, J. P. (2010). An Introduction to Discourse Analysis: Theory and Method. Taylor \& Francis. https://doi.org/10.4324/9780203847886

Givon, T. (1995). Functionalism and grammar. Amsterdam: John Benjamins. https://doi.org/10.1075/z.74

Gutwinski, W. (1976). Cohesion in Literary Texts. The Hague: Mouton. https://doi.org/10.1515/9783111352176

Gudykunst, W. B., Ting-Toomey, S., \& Chua, E. (1988). Culture and interpersonal communication. Newbury Park, CA: Sage.

Gudykunst, W. B., \& Mody, B. (Eds.). (2002). Handbook of International and Intercultural Communication (2nd ed.). Thousand Oaks, CA: Sage.

Hall, E. T. (1976). Beyond Culture. New York: Doubleday.

Hall, E. T., \& Hall, M. R. (1990). Understanding Cultural Differences. Yarmouth, ME: Intercultural Press Inc.

Hall, E. T. (2000). Context and Meaning. In L. A. Samovar, \& R. E. Porter (Eds.), Intercultural Communication: A Reader (9th ed., pp. 34-43). Belmont, CA: Wadsworth Publishing Co.

Halliday, M., \& Hasan, R. (1976). Cohesion in English. London: Longman.

Halliday, M. (1994). An Introduction to Functional Grammar (2nd ed.). London et al.: Edward Arnold.

Halliday, M. (1985). Systemic Background. In J. D. Benson, \& W. S. Greaves (Eds.), Systemic Perspectives on Discourse, 1. (ADPS15).

Hu, S. J. (2014). Introductory of Translation for Beginners. Taipei: Showway information.

I. A. Richards (1937). The Philosophy of Rhetoric. New York: Oxford University Press.

Kaplan, R. (1966). Cultural thought patterns in intercultural education. Language Learning, 16, 1-20. https://doi.org/10.1111/j.1467-1770.1966.tb00804.x

Kim, D., Pan, Y., \& Park, H. S. (1998). High- versus low- context culture: A comparison of Chinese, Korean and American cultures. Psychology \& Marketing, 15(6), 507-521. https://doi.org/10.1002/(SICI)1520-6793 (199809)15:6\%3C507::AID-MAR2\%3E3.0.CO;2-A

Kim, M. (2007). Using Systemic Functional Text Analysis for Translator Education: An Illustration with a Focus on the Textual Meaning. Interpreter and Translator Trainer, 1, 223-246. https://doi.org/10.1080/ 1750399X.2007.10798759

Lichao, C. (2007). (Simplified) Chinese Translation for Randy Pausch's Last Lecture: Really Achieving Your Childhood Dreams.

Pausch, R. (2007, December 20). Randy Pausch Last Lecture: Achieving Your Childhood Dreams. Carnegie Mellon University. Retrieved from https://www.youtube.com/watch?v=ji5_MqicxSo

Pausch, R., \& Zaslow, J. (2008). The Last Lecture. Hyperion: New York.

Pausch, R., \& Zaslow, J. (2008). The Last Lecture (H. Chen, Trans.). Taipei: Fang-zhi Publisher. (Traditional Chinese).

Pausch, R. (2007). The Last Lecture, Carnegie Mellon University. The script retrieved from SPEAKINGFROG: http://speakingfrog.com/?p=383

Richards J. C. (2000). Longman Dictionary of Language Teaching \& Applied Linguistics. Beijing: Foreign Language Teaching and Research Press.

Shih, H. C. (2008). Text analysis in translation practice: An approach through M. A. K Halliday's functional grammar. Journal of Applied Foreign Languages, 9, 35-54. 
Si-Guo (1972). Study of Translation (Chinese Traditional Version). Taiwan: The Earth Press.

Stubbs, M. (1983). Discourse Analysis. Oxford: Blackwell.

van Dijk, T. A. (2004.) Text and Context of Parliamentary Debates. In P. Bayley (Ed.), Cross-cultural Perspective on Parliamentary Discourse (pp. 339-72). Amsterdam: Benjamins. https://doi.org/10.1075/ dapsac.10.10dij

van Dijk, T. A. (2005). Contextual Knowledge Management in Discourse Production. CDA Perspective. In R. Wodak, \& P. Chilton (Eds.), A New Agenda in (Critical) Discourse Analysis (pp. 71-100). Amsterdam: Benjamins. https://doi.org/10.1075/dapsac.13.07dij

Wang Y. L. (2008). Application of Theme-Rheme Theory on Teaching College Writing. Cross-cultural Communication, 4(2), 106-108.

Widdowson, H. G. (1978). Teaching Language as Communication. Oxford: Oxford University Press.

Yu, Y. L. (2007). Difference between Cohesions of English and Chinese Context and Their Translation. Cross-cultural Communication, 3(2), 32-36.

Notes

Note 1. This is a representation of a PowerPoint slide taken from Dr. Pausch's lecture

Note 2. The pen name of "Frederick" Tsai Chuo-tang.

\section{Copyrights}

Copyright for this article is retained by the author(s), with first publication rights granted to the journal.

This is an open-access article distributed under the terms and conditions of the Creative Commons Attribution license (http://creativecommons.org/licenses/by/4.0/). 